\title{
Factors Associated with Early Mortality in Critically Ill Patients Following the Initiation of Continuous Renal Replacement Therapy
}

\author{
Youn Kyung Kee ${ }^{1}$, Dahye Kim ${ }^{2}$, Seung-Jung Kim ${ }^{3}$, Duk-Hee Kang ${ }^{3}$, Kyu Bok Choi ${ }^{3}$, \\ Hyung Jung Oh 4,5,* and Dong-Ryeol Ryu ${ }^{3,4,6, *}$
}

1 Department of Internal Medicine, Hangang Sacred Heart Hospital, Hallym University College of Medicine, Seoul 07247, Korea; no7766@yuhs.ac

2 Department of Nursing, Ewha Womans University Mokdong Hospital, Seoul 07985, Korea; dahye7738@gmail.com

3 Department of Internal Medicine, School of Medicine, Ewha Womans University, Seoul 03761, Korea; sjkimwon@ewha.ac.kr (S.-J.K.); dhkang@ewha.ac.kr (D.-H.K.); kbchoi@ewha.ac.kr (K.B.C.)

4 Research Institute for Human Health Information, Ewha Womans University Mokdong Hospital, Seoul 07985, Korea

5 Ewha Institute of Convergence Medicine, Ewha Womans University Mokdong Hospital, Seoul 07985, Korea

6 Tissue Injury Defense Research Center, College of Medicine, Ewha Womans University, Seoul 07985, Korea

* Correspondence: ohjmd@naver.com (H.J.O.); drryu@ewha.ac.kr (D.-R.R.); Tel.: +82-2-2650-2907 (H.J.O. \& D.-R.R.); Fax: +82-2-2650-2908 (H.J.O.); +82-2-2650-2501 (D.-R.R.)

Received: 12 September 2018; Accepted: 5 October 2018; Published: 8 October 2018

check for updates

\begin{abstract}
Continuous renal replacement therapy (CRRT) is an important modality to support critically ill patients, and the need for CRRT treatment has been increasing. However, CRRT management is costly, and the associated resources are limited. Thus, it remains challenging to identify patients that are likely to have a poor outcome, despite active treatment with CRRT. We sought to elucidate the factors associated with early mortality after CRRT initiation. We analyzed 240 patients who initiated CRRT at an academic medical center between September 2016 and January 2018. We compared baseline characteristics between patients who died within seven days of initiating CRRT (early mortality), and those that survived more than seven days beyond the initiation of CRRT. Of the patients assessed, $130(54.2 \%)$ died within seven days of CRRT initiation. Multivariate logistic regression models revealed that low mean arterial pressure, low arterial $\mathrm{pH}$, and high Sequential Organ Failure Assessment score before CRRT initiation were significantly associated with increased early mortality in patients requiring CRRT. In conclusion, the mortality within seven days following CRRT initiation was very high in this study. We identified several factors that are associated with early mortality in patients undergoing CRRT, which may be useful in predicting early outcomes, despite active treatment with CRRT.
\end{abstract}

Keywords: continuous renal replacement therapy; early mortality; clinical illness

\section{Introduction}

Acute kidney injury (AKI) is a major complication in critically ill patients, and it is associated with high mortality [1-3]. Continuous renal replacement therapy (CRRT) is a widely chosen treatment option in AKI patients requiring renal replacement therapy (RRT), particularly for hemodynamically unstable patients with considerable fluid accumulation [4-6]. Although CRRT is commonly considered as an initial option for critically ill patients who need RRT, the cost of CRRT treatment is higher than that of intermittent RRT, and CRRT-associated resources are limited $[7,8]$. 
Despite advances in CRRT techniques over the last several years, the mortality rate of patients undergoing CRRT remains high [9-12]. Many studies have investigated the benefit of CRRT treatment with regard to clinical outcomes and assessed potential prognostic factors for mortality [13-15]. Several factors, including sepsis, high acute physiology, and chronic health evaluation (APACHE) II score and/or sequential organ failure assessment (SOFA) score, poor urine output before CRRT initiation, comatose state, need for mechanical ventilation, fluid overload status, and type of CRRT solution are associated with increased mortality rate [16-22]. However, some patients die within one week of CRRT initiation, causing physicians to often doubt the benefits of such an invasive procedure on patient survival and/or renal preservation. Unfortunately, there are few studies to determine which factors are associated with increased early mortality in critically ill patients undergoing CRRT.

Considering the high cost and the limited resources available, identification of patients who would be more likely to have a poor outcome despite active treatment with CRRT is necessary to make an informed decision for patients requiring RRT. Thus, the aim of this study was to investigate the factors that are associated with increased early mortality, which we defined as death in the 7 days following CRRT initiation.

\section{Methods}

\subsection{Study Population}

This was a retrospective observational study of patients aged 18 years or older who initiated CRRT at a tertiary academic medical center between September 2016 and January 2018. Patients who were younger than 18 years, who were undergoing chronic dialysis due to end-stage renal disease, or who had a less than 3 month life expectancy due to malignancy were excluded. Ultimately, 240 patients were enrolled and assessed to determine the factors that were associated with early mortality in critically ill patients undergoing CRRT. We defined 'early mortality' as mortality within seven days of CRRT initiation. In addition, we defined 'very early mortality' as mortality within $24 \mathrm{~h}$ of CRRT initiation. This study was approved by the Institutional Review Board of Ewha Womans University, College of Medicine, and informed consent was waived because it was a retrospective cohort study.

\subsection{Data Collection}

Baseline characteristics were age, sex, body mass index (BMI), systolic blood pressure (SBP), diastolic blood pressure (DBP), mean arterial pressure (MAP), heart rate, comorbidities, Charlson Comorbidity Index (CCI) [23], SOFA score, and laboratory diagnostic data collected at the start of CRRT. Moreover, estimated glomerular filtration rate (eGFR) was calculated using the IDMS-traceable Modification of Diet in Renal Disease equation [24]. The presence of systemic inflammatory response syndrome (SIRS) [25]. APACHE II score and one-hour urine output immediately before CRRT initiation was also investigated. As a parameter for acute lung injury (ALI), patients with $\mathrm{PaO}_{2} / \mathrm{FiO}_{2} \leq 300 \mathrm{mmHg}$ were evaluated. Data from patients collected until 28 days after CRRT initiation was used, and their survival or all-cause mortality was examined during this period.

\subsection{CRRT Protocol}

The decision to initiate the CRRT and the CRRT settings of target clearance, blood flow, dialysate, and replacement fluid rates, and anticoagulation administration were determined through discussion and consultation with nephrologists. The criteria for CRRT initiation were medically intractable or persistent electrolyte imbalance and/or metabolic acidosis, and decreased urine output with volume overload and/or progressive azotemia. Hemodynamic instability was also an important indication. Generally, vascular access for CRRT was via a femoral venous catheter, and the predilution method of continuous venovenous hemodiafiltration was usually performed. Blood flow was gradually increased from an initial rate of 100 to $150 \mathrm{~mL} / \mathrm{min}$ according to the hemodynamic status of the patient. Although the target clearance was $35-40 \mathrm{~mL} / \mathrm{kg} / \mathrm{h}$ in most patients, this target was increased 
to $60 \mathrm{~mL} / \mathrm{kg} / \mathrm{h}$ or higher in patients with severe sepsis or septic shock if possible [26]. Additionally, the anticoagulant administered was selected by nephrologists, and they were dependent on bleeding tendency or contraindications to conventional heparin. After CRRT initiation, attending physicians and experienced nurses monitored the body weight, urine output, laboratory results, actual delivered dose, and the hemodynamic status of the patients, and discussed the results with nephrologists to maintain the adequacy of CRRT.

\subsection{Statistical Analysis}

Continuous variables are expressed as the mean and standard deviation (SD), and categorical variables as number and percentage. Chi-square tests for categorical variables and Student's t-test for continuous variables were used to compare baseline data between the two groups. We also performed univariate and multivariate logistic regression analyses to determine the factors associated with early or very early mortality. All statistical analyses were performed using SPSS version 23 software (SPSS, Chicago, IL, USA), and all $p$-values were two-tailed, with a predetermined alpha level $<0.05$ being considered statistically significant.

\section{Results}

\subsection{Baseline Characteristics}

Baseline demographic and clinical characteristics of these study patients are described in Table 1. For the 240 patients assessed, the mean age was $65.8 \pm 14.7$ years, and 150 patients $(62.5 \%)$ were male. Mean SBP, DBP, and MAP were 112.5, 64.1, and $80.2 \mathrm{mmHg}$, respectively. In addition, there were 45 patients $(18.8 \%)$ who had MAPs of less than $65 \mathrm{mmHg}$. Of the patients, $128(53.3 \%)$ had hypertension, $89(37.1 \%)$ were diagnosed with diabetes mellitus (DM), and the mean CCI was $6.6 \pm 2.3$. The mean volume of 1-hour urine outputs before CRRT was $27.2 \pm 56.8 \mathrm{~mL}$, and the mean APACHE II and SOFA scores were $26.1 \pm 6.8$ and $11.6 \pm 3.9$, respectively.

Table 1. Baseline characteristics of study patients.

\begin{tabular}{|c|c|c|c|c|}
\hline \multirow{2}{*}{ Variables } & Total & 7-Day Mortality & 7-Day Survivors & \multirow{2}{*}{$p$ Value } \\
\hline & $(n=240,100 \%)$ & $(n=130,54.2 \%)$ & $(n=110,45.8 \%)$ & \\
\hline Age (year) & $65.8 \pm 14.7$ & $65.9 \pm 14.2$ & $65.7 \pm 15.3$ & 0.928 \\
\hline Male sex, $n(\%)$ & $150(62.5)$ & $78(60.0)$ & $72(65.5)$ & 0.231 \\
\hline $\mathrm{BMI}\left(\mathrm{kg} / \mathrm{m}^{2}\right)$ & $23.1 \pm 4.3$ & $23.0 \pm 4.7$ & $23.1 \pm 3.7$ & 0.850 \\
\hline SBP (mmHg) & $112.5 \pm 23.9$ & $107.3 \pm 22.6$ & $118.6 \pm 24.2$ & $<0.001$ \\
\hline $\mathrm{DBP}(\mathrm{mmHg})$ & $64.1 \pm 15.2$ & $61.9 \pm 14.1$ & $66.8 \pm 16.1$ & 0.013 \\
\hline MAP (mmHg) & $80.2 \pm 16.0$ & $77.0 \pm 15.1$ & $84.0 \pm 16.3$ & 0.001 \\
\hline $\mathrm{MAP}<65 \mathrm{mmHg}, n(\%)$ & $45(18.8)$ & $32(24.6)$ & $13(11.8)$ & 0.008 \\
\hline Heart rate (per min) & $107.2 \pm 24.0$ & $110.7 \pm 22.5$ & $103.1 \pm 25.2$ & 0.015 \\
\hline \multicolumn{5}{|l|}{ Comorbidity disease } \\
\hline Hypertension, $n(\%)$ & $128(53.3)$ & $65(50.0)$ & $47(42.7)$ & 0.160 \\
\hline Diabetes mellitus, $n(\%)$ & $89(37.1)$ & $43(33.1)$ & $46(41.8)$ & 0.103 \\
\hline $\mathrm{CHF}, n(\%)$ & $15(6.3)$ & $9(6.9)$ & $6(5.5)$ & 0.423 \\
\hline COPD, $n(\%)$ & $4(1.7)$ & $2(1.8)$ & $2(1.5)$ & 0.624 \\
\hline Age CCI & $6.60 \pm 2.31$ & $6.50 \pm 2.42$ & $6.72 \pm 2.18$ & 0.468 \\
\hline SIRS, $n(\%)$ & $199(82.9)$ & $114(87.7)$ & $85(77.3)$ & 0.025 \\
\hline Sepsis, $n(\%)$ & $75(31.3)$ & $42(32.3)$ & $33(30.0)$ & 0.404 \\
\hline Amount of $1-\mathrm{h}$ UO (mL) & $27.2 \pm 56.8$ & $26.6 \pm 60.1$ & $27.8 \pm 52.9$ & 0.879 \\
\hline APACHE II score & $26.1 \pm 6.8$ & $28.9 \pm 6.2$ & $22.9 \pm 6.0$ & $<0.001$ \\
\hline SOFA score & $11.58 \pm 3.87$ & $12.70 \pm 3.53$ & $10.27 \pm 3.86$ & $<0.001$ \\
\hline
\end{tabular}

Data are presented as mean \pm standard deviation or number (\%). Abbreviations: BMI, body mass index; SBP, systolic blood pressure; DBP, diastolic blood pressure; MAP, mean arterial blood pressure; $\mathrm{CHF}$, congestive heart failure; COPD, chronic obstructive heart failure; CCI, Charlson comorbidity index; SIRS, systemic inflammatory response syndrome; $\mathrm{UO}$, urine output. 
When we divided these patients into two groups (early mortality vs. 7-day survival past CRRT initiation), 138 (54.2\%) died within seven days following the start of CRRT, and 110 (45.8\%) survived more than seven days following CRRT initiation. There were no significant differences in age, sex distribution, BMI, the prevalence of underlying diseases, CCI, or 1-h urine volume output at baseline between the two groups. The proportion of patients diagnosed with sepsis was also not significantly different between the two groups.

However, SBP, DBP, and MAP were significantly lower in the patients that exhibited early mortality following CRRT initiation compared to 7-day survivors. Additionally, heart rate and APACHE II and SOFA scores were significantly higher in the early mortality group compared to those of 7-day survivors. Finally, we observed that a higher proportion of patients suffered from SIRS in the early mortality group compared to the 7-day survivor group.

Table 2 shows laboratory data of the patients at baseline. The mean white blood cell count was $13,100 / \mu \mathrm{L}$; the mean hemoglobin was $9.4 \pm 2.1 \mathrm{~g} / \mathrm{dL}$; and serum sodium, potassium, and bilirubin levels were $138.9 \pm 7.3,4.5 \pm 1.0$, and $2.8 \pm 4.9 \mathrm{mEq} / \mathrm{L}$, respectively. Additionally, the mean aspartate transaminase (AST) and alanine transaminase (ALT) levels were $401.8 \pm 1157.2$ and $158.8 \pm 575.5 \mathrm{IU} / \mathrm{L}$, respectively, and the mean eGFR was $22.7 \pm 17.1 \mathrm{ml} / \mathrm{min} / 1.73 \mathrm{~m}^{2}$. The mean arterial $\mathrm{pH}$ was $7.29 \pm 0.13$, and the base excess was $-7.74 \pm 7.10 \mathrm{mmol} / \mathrm{L}$. When these data were compared between the early mortality and the 7-day survivor groups, serum phosphate level was significantly higher, while arterial $\mathrm{pH}$ was significantly lower in the early mortality group compared to the survivor group. Moreover, there was a higher proportion of patients with $\mathrm{pH}<7.35$ in the early mortality group than in the survivor group, and base excess was lower (base excess $=-8.88$ ) in the early mortality group compared to the survivor group (base excess $=-6.43$ ). Meanwhile, there was no difference in the proportion of patients with $\mathrm{PaO}_{2} / \mathrm{FiO}_{2} \leq 300 \mathrm{mmHg}$ between groups. The baseline characteristics and laboratory findings of patients with very early mortality were additionally described in Supplementary Materials (Tables S1 and S2).

Table 2. Baseline laboratory data of study patients.

\begin{tabular}{|c|c|c|c|c|}
\hline \multirow{2}{*}{ Variables } & Total & 7-Day Mortality & 7-Day Survivors & \multirow{2}{*}{$p$ Value } \\
\hline & $(n=240,100 \%)$ & $(n=130,54.2 \%)$ & $(n=110,45.8 \%)$ & \\
\hline WBC $(103 / \mu \mathrm{L})$ & $13.1 \pm 12.3$ & $14.1 \pm 15.5$ & $11.9 \pm 7.1$ & 0.147 \\
\hline Hemoglobin (g/dL) & $9.4 \pm 2.1$ & $9.5 \pm 2.3$ & $9.4 \pm 1.9$ & 0.892 \\
\hline Platelet $(103 / \mu \mathrm{L})$ & $127.8 \pm 86.5$ & $127.9 \pm 89.1$ & $127.6 \pm 83.8$ & 0.980 \\
\hline Sodium (mEq/L) & $138.9 \pm 7.3$ & $139.6 \pm 7.9$ & $138.1 \pm 6.4$ & 0.119 \\
\hline Potassium $(\mathrm{mEq} / \mathrm{L})$ & $4.5 \pm 1.0$ & $4.6 \pm 1.0$ & $4.5 \pm 0.9$ & 0.289 \\
\hline Calcium (mg/dL) & $7.8 \pm 1.3$ & $7.7 \pm 1.2$ & $7.8 \pm 1.4$ & 0.669 \\
\hline Phosphate (mg/dL) & $5.5 \pm 2.9$ & $5.9 \pm 3.2$ & $5.0 \pm 2.5$ & 0.021 \\
\hline Bilirubin, total (mg/dL) & $2.8 \pm 4.9$ & $2.9 \pm 4.9$ & $2.6 \pm 4.8$ & 0.568 \\
\hline $\mathrm{AST}(\mathrm{IU} / \mathrm{L})$ & $401.8 \pm 1157.2$ & $416.8 \pm 1012.7$ & $384.5 \pm 1308.8$ & 0.831 \\
\hline $\operatorname{ALT}(\mathrm{IU} / \mathrm{L})$ & $185.8 \pm 575.5$ & $199.1 \pm 473.4$ & $170.6 \pm 675.7$ & 0.706 \\
\hline eGFR $\left(\mathrm{ml} / \mathrm{min} / 1.73 \mathrm{~m}^{2}\right)$ & $22.7 \pm 17.1$ & $23.7 \pm 16.2$ & $21.4 \pm 18.1$ & 0.300 \\
\hline $\mathrm{pH}$ & $7.29 \pm 0.13$ & $7.25 \pm 0.12$ & $7.33 \pm 0.12$ & $<0.001$ \\
\hline $\mathrm{pH}<0.35, n(\%)$ & $164(68.3)$ & $107(82.3)$ & $57(51.8)$ & $<0.001$ \\
\hline $\mathrm{BE}(\mathrm{mmol} / \mathrm{L})$ & $-7.75 \pm 7.10$ & $-8.88 \pm 6.64$ & $-6.43 \pm 7.43$ & 0.008 \\
\hline $\mathrm{PaO}_{2} / \mathrm{FiO}_{2}<300$ & $188(78.3)$ & $106(81.5)$ & $82(74.5)$ & 0.125 \\
\hline
\end{tabular}

Data are presented as mean \pm standard deviation or number (\%). Abbreviations: WBC, whole blood cell; AST, aspartate aminotransferase; ALT, alanine aminotransferase; eGFR, estimated glomerular filtration rate; BE, base excess.

\subsection{Factors Associated with Early Mortality}

In this study, 162 patients (67.5\%) died in the 28 days following CRRT initiation, and most of those deaths occurred in the early period following CRRT initiation (Figure 1). Specifically, 130 patients $(80.2 \%)$ died within seven days following CRRT initiation, with 54 of those patients dying within $24 \mathrm{~h}$ following CRRT initiation. 


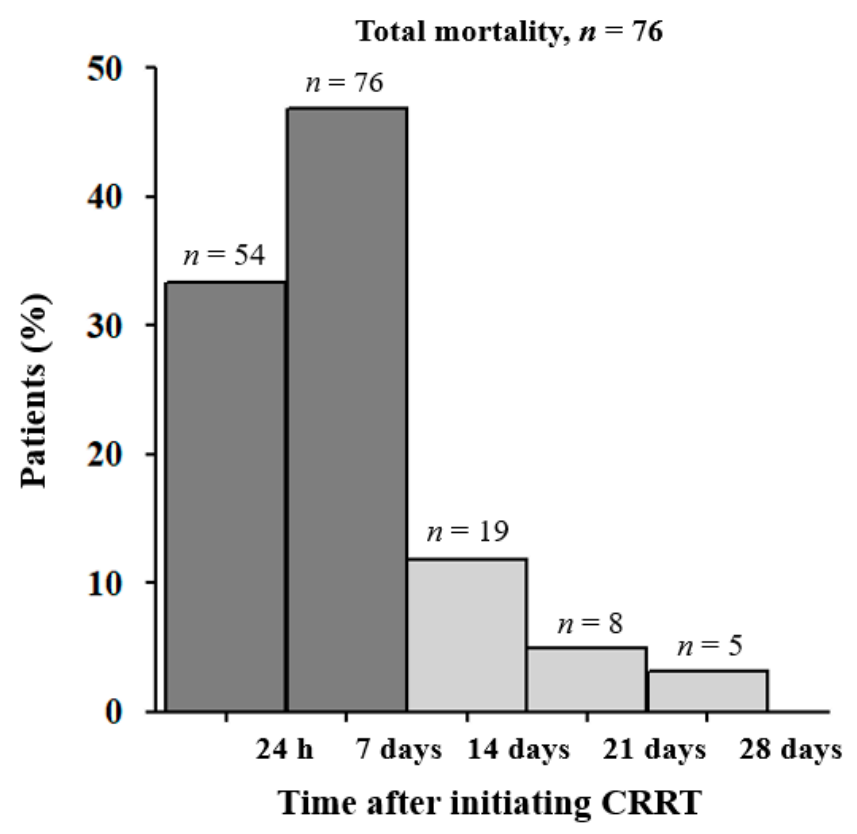

Figure 1. Mortality rate according to time after continuous renal replacement therapy (CRRT) initiation.

By univariate logistic regression analysis, patients with MAP $<65 \mathrm{mmHg}$ and SIRS had an odds ratio (OR) of 2.436 (95\% CI; 1.206-4.922, $p=0.013$ ) and OR of 2.096 (95\% CI; 1.054-4.168, $p=0.035$ ) for an increased risk of early mortality, compared to patients with $\mathrm{MAP}>65 \mathrm{mmHg}$, and an absence of SIRS. Moreover, a 1-SD increase of serum phosphate was significantly associated with an increased risk of early mortality ( $\mathrm{OR}=1.393,95 \% \mathrm{CI}(1.044-1.858), p=0.024)$, and a 1-SD increase in SOFA score was also significantly associated with an increased incidence of early mortality (OR $=1.992,95 \% \mathrm{CI}$ (1.488-2.668), $p<0.001)$. Finally, the patients with $\mathrm{pH}<7.35$ also had a higher risk of early mortality compared to those with $\mathrm{pH}>7.35$ (OR $=4.326,95 \% \mathrm{CI}(2.409-7.768), p<0.001)$. Importantly, after adjustment for demographic factors and other factors found to associate by univariate analysis with early mortality, increased SOFA score, low MAP $(<65 \mathrm{mmHg})$, and low arterial $\mathrm{pH}(<7.35)$ all remained significantly associated with an increased risk of early mortality (SOFA score; OR $=1.758,95 \% \mathrm{CI}$ (1.282-2.412), $p<0.001$, low MAP; OR = 2.771, 95\% CI (1.213-6.327), $p=0.016$, and low $\mathrm{pH} ; \mathrm{OR}=3.067$, 95\% CI (1.593-5.903), $p=0.001$ ) (Table 3). With consideration for overlapping parts between MAP, SIRS, and SOFA scores, additional multivariate regression analyses were performed by adjusting one of these three parameters to add to the other variables. As a result, SIRS showed a loss of significance, even in the analysis, without adjustment with MAP and SOFA scores.

We also performed multivariate logistic regression analyses to assess factors associated with very early mortality, to determine the similarities and differences between those factors related to the increased early mortality. We found that an increased serum sodium level, phosphate level, SOFA score, and low MAP $(<65 \mathrm{mmHg}$ ) were all significantly associated with increased very early mortality, even after multivariate adjustment, as described previously (Table 4). Therefore, low MAP and increased SOFA scores are associated with an increased risk of both early and very early mortality. 
Table 3. Logistic regression analysis for early mortality *.

\begin{tabular}{lcccc}
\hline \multirow{2}{*}{\multicolumn{1}{c}{ Factors }} & \multicolumn{2}{c}{ Univariate } & \multicolumn{2}{c}{ Multivariate } \\
\cline { 2 - 5 } & OR (95\% CI) & $p$ Value & OR (95\% CI) & $p$ Value \\
\hline Age (per 1-SD increase) & $1.012(0.785-1.305)$ & 0.928 & $1.079(0.803-1.450)$ & 0.614 \\
Male (versus Female) & $0.792(0.467-1.341)$ & 0.385 & $0.877(0.477-1.610)$ & 0.671 \\
BMI (per 1-SD increase) & $0.976(0.757-1.259)$ & 0.976 & $0.929(0.695-1.240)$ & 0.616 \\
MAP < 65 mmHg (versus MAP $\geq \mathbf{6 5 ~} \mathbf{m m H g})$ & $2.436(1.206-4.922)$ & 0.013 & $2.771(1.213-6.327)$ & 0.016 \\
SIRS (versus no SIRS) & $2.096(1.054-4.168)$ & 0.035 & $1.602(0.717-3.583)$ & 0.251 \\
Sepsis (versus no sepsis) & $0.898(0.519-1.555)$ & 0.898 & - & - \\
Phosphate (per 1-SD increase) & $1.393(1.044-1.858)$ & 0.024 & $1.197(0.869-1.649)$ & 0.270 \\
pH < 7.35 (versus pH $\geq$ 7.35) & $4.326(2.409-7.768)$ & $<0.001$ & $3.067(1.593-5.903)$ & 0.001 \\
SOFA score (per 1-SD increase) & $1.992(1.488-2.668)$ & $<0.001$ & $1.758(1.282-2.412)$ & $<0.001$ \\
\hline
\end{tabular}

* The early mortality was defined by the death within seven days after CRRT initiation. Abbreviations: OR, odds ratio; $\mathrm{CI}$, confidential interval; $\mathrm{SD}$, standard deviation; BMI, body mass index; MAP, mean arterial blood pressure; SIRS, systemic inflammatory response syndrome

Table 4. Logistic regression analysis for very early mortality *.

\begin{tabular}{lcccc}
\hline & \multicolumn{2}{c}{ Univariate } & \multicolumn{2}{c}{ Multivariate } \\
\cline { 2 - 5 } \multicolumn{1}{c}{ Factors } & OR (95\% CI) & $p$ Value & OR (95\% CI) & $p$ Value \\
\hline Age (per 1-SD increase) & $1.069(0.785-1.456)$ & 0.672 & $1.363(0.909-2.043)$ & 0.134 \\
Male (versus female) & $0.632(0.337-1.151)$ & 0.131 & $0.707(0.327-1.532)$ & 0.380 \\
BMI (per 1-SD increase) & $1.038(0.768-1.402)$ & 0.810 & $0.956(0.657-1.391)$ & 0.816 \\
Diabetes mellitus (versus non-diabetes) & $0.354(0.172-0.730)$ & 0.005 & $0.456(0.189-1.101)$ & 0.081 \\
MAP < 65 mmHg (versus MAP $\geq \mathbf{6 5}$ mmHg) & $4.295(2.144-8.607)$ & $<0.001$ & $8.498(3.379-21.375)$ & $<0.001$ \\
SIRS (versus no SIRS) & $2.352(0.874-6.326)$ & 0.090 & - & - \\
Sepsis (versus no sepsis) & $1.103(0.570-2.136)$ & 0.770 & - & - \\
Sodium (per 1-SD increase) & $1.458(1.202-1.769)$ & $<0.001$ & $1.588(1.241-2.031)$ & $<0.001$ \\
Phosphate (per 1-SD increase) & $1.632(1.207-2.207)$ & 0.001 & $1.669(1.149-2.424)$ & 0.007 \\
pH < 7.35 (versus pH $\geq$ 7.35) & $4.828(1.965-11.863)$ & 0.001 & $2.395(0.860-6.675)$ & 0.095 \\
SOFA score (per 1-SD increase) & $1.895(1.329-2.702)$ & $<0.001$ & $1.691(1.049-2.725)$ & 0.031 \\
\hline \multicolumn{2}{c}{ * Very early mortality was defined by death within 24 h after CRRT initiation. Abbreviations: OR, odds ratio; CI, } \\
$\quad$ confidential interval; SD, standard deviation; BMI, body mass index; MAP, mean arterial blood pressure; SIRS, \\
$\quad$ systemic inflammatory response syndrome
\end{tabular}

\section{Discussion}

This study demonstrated that early mortality within seven days following CRRT initiation was high in critically ill patients undergoing CRRT (54.2\%). Moreover, MAP $<65 \mathrm{mmHg}$, arterial $\mathrm{pH}<7.35$, and high SOFA score at CRRT initiation significantly associated with increased risk of early mortality in these patients.

When we stratified the mortality rate of critically ill patients undergoing CRRT initiation, $80.2 \%$ of the total 162 patients that died during the 28-day follow-up period died within seven days following CRRT initiation, and 33.3\% (54/162 patients) died within $24 \mathrm{~h}$ following CRRT initiation. A smaller percentage of patients, 19.8\% (32/162 patients), died between eight and 28 days following CRRT initiation. Thus, we assessed which factors were associated with early or very early mortality in this group.

There are many studies assessing prognostic factors for the mortality risk of CRRT to predict and prevent poor clinical outcomes [13-22]. However, most of these studies assessed mortality beyond 28 days post-initiation of CRRT. Only a few studies have been conducted to investigate early mortality among critically ill patients undergoing CRRT $[27,28]$. In contrast, clinicians are often challenged to determine the benefit of CRRT, and it is difficult to identify patients that are more likely to demonstrate poor clinical outcomes, despite active treatment with CRRT to make the best decision for patients requiring RRT.

In this study, MAP $<65 \mathrm{mmHg}$, arterial $\mathrm{pH}<7.35$, and high SOFA score at CRRT initiation were risk factors for early mortality. Additionally, $\mathrm{MAP}<65 \mathrm{mmHg}$, increased serum sodium, and phosphate levels, and high SOFA score at CRRT initiation, were significantly associated with an 
increased rate of very early mortality. Above these factors can be found in the other studies which were performed for the 28-, 60-, or 90-day mortality, which means that such factors may be more likely to be issued for early mortality.

CRRT treatment is primarily considered for patients in critical condition, who are hemodynamically unstable, and/or who suffer from increased intracranial pressure due to acute brain injury [29,30]; thus, the mortality rate of patients requiring CRRT is generally high. The mortality rate within hours or days following CRRT initiation is particularly high, mainly due to the poor condition of the patients at the initiation of CRRT. Specifically, Passos et al. [31] demonstrated a 7-day mortality of $45.0 \%$ (84/186 patients), and Prasad et al. [27] reported that 16.0\% (17/106 patients) died within $24 \mathrm{~h}$ after the start of CRRT. In this study, $22.5 \%$ (54/240 patients) died within $24 \mathrm{~h}$, and $54.2 \%$ (130/240 patients) died within seven days following CRRT initiation. Moreover, $80.2 \%$ of the total number of patients that died within the 28-day period (130/162 patients) died within 7 days following CRRT initiation. To our knowledge, this is the first study comparing the mortality rate at different time periods following CRRT initiation, and these results suggest that a majority of patients undergoing CRRT die within seven days following initiation. However, a prospective cohort study with a larger population should be performed to confirm these results.

AKI, combined with cardiovascular instability, fluid overload, cerebral edema, and high fluid requirement, generally indicates a need for CRRT [32,33]. In addition, the need to eliminate inflammatory mediators, remove fluid, or eliminate other endogenous toxic solutes have been presented as non-renal reasons to initiate CRRT [34]. In our study, several factors were found to be associated with early or very early mortality in patients undergoing CRRT. MAP is a hemodynamic parameter, and maintaining MAP $\geq 65 \mathrm{mmHg}$ is recommended in the management of patients with septic shock, a condition for which CRRT is a common treatment [35]. In addition, a SOFA score represents a severity parameter and it is a widely accepted prognostic factor for critically ill patients $[36,37]$. Several studies report a significant association between a high SOFA score at CRRT initiation, and increased mortality [38-40]. Arterial $\mathrm{pH}$ is one of the variables that is considered in the APACHE II score, which was designed to measure the disease severity and the risk of death in critically ill patients, and several studies have demonstrated that arterial $\mathrm{pH}$ is associated with increased mortality in patients undergoing CRRT [41-43]. In addition, previous studies have reported that hypernatremia and hyperphosphatemia are common in critically ill patients, and they were associated with increased morbidity and mortality [44-47]. The factors identified in this study could be predictable through previous studies; however, this study has significance because it reaffirms the clinical importance of these factors by assessing the association with early death showing high mortality rate. The results presented here do not indicate the futility of CRRT treatment for patients with lower MAP, lower $\mathrm{pH}$, higher serum sodium or phosphate, or high SOFA score. However, these results could be useful in predicting the prognosis of critically ill patients after CRRT initiation.

There are some limitations to our study. First, this was a single center study with a relatively small sample size, so we cannot rule out selection bias, and these results may not be generalizable to other populations. Therefore, a future multiple-center study with a larger sample size is warranted to verify factors that are associated with early mortality in critically ill patients undergoing CRRT. Second, because of the inherent limitations of a retrospective study, other potential factors associated with early death in critically ill patients, such as causes of CRRT initiation or primary diagnosis at admission may not have been assessed. Third, we investigated mortality events based on arbitrarily stratified time periods, such as within $24 \mathrm{~h}, 7$ days, or 28 days following CRRT initiation, and defined 'early mortality' or 'very early mortality' discretionally. However, several studies for mortality of the patients undergoing CRRT have used 28-days mortality as the end-point and there have been also some studies for 24-hour and 7-day mortality, so that these timeframes are not without precedent. Moreover, in this study, we found that the highest mortality following CRRT occurred in the early timeframe following CRRT initiation. Lastly, this observational study does not allow us to conclude a causal relationship, 
and it only demonstrates the associations between clinical factors and early or very early mortality in patients undergoing CRRT treatment.

\section{Conclusions}

In conclusion, we found that the early mortality rate within seven days following CRRT initiation was very high in this cohort of critically ill patients undergoing CRRT. Moreover, low MAP, low arterial $\mathrm{pH}$, and high SOFA score at CRRT initiation were associated with early mortality in these patients. Although these factors may not be used as determinants in deciding whether or not CRRT should be initiated in critically ill patients, they may be useful in predicting early or very early mortality despite active treatment with CRRT.

Supplementary Materials: The following are available online at http:/ /www.mdpi.com/2077-0383/7/10/334/s1, Table S1: Baseline characteristics of study subjects, Table S2: Laboratory data of study subjects at baseline.

Author Contributions: D.-R.R. originated the concept for this study. K.B.C. and D.-H.K. contributed to the study design and coordination of the study. Y.K.K. and H.J.O. drafted the manuscript and conducted the analyses. D.K. and S.-J.K. maintained the patient database and assisted in data analysis. All authors read and approved final manuscript.

Funding: This research received no external funding.

Conflicts of Interest: The authors declare no conflict of interest.

\section{References}

1. Liangos, O.; Wald, R.; O’Bell, J.W.; Price, L.; Pereira, B.J.; Jaber, B.L. Epidemiology and outcomes of acute renal failure in hospitalized patients: A national survey. Clin. J. Am. Soc. Nephrol. 2006, 1, 43-51. [CrossRef] [PubMed]

2. Uchino, S.; Kellum, J.A.; Bellomo, R.; Doig, G.S.; Morimatsu, H.; Morgera, S.; Schetz, M.; Tan, I.; Bouman, C.; Macedo, E.; et al. Acute renal failure in critically ill patients: A multinational, multicenter study. JAMA 2005, 294, 813-818. [CrossRef] [PubMed]

3. Bagshaw, S.M.; Laupland, K.B.; Doig, C.J.; Mortis, G.; Fick, G.H.; Mucenski, M.; Godinez-Luna, T.; Svenson, L.W.; Rosenal, T. Prognosis for long-term survival and renal recovery in critically ill patients with severe acute renal failure: A population-based study. Crit. Care 2005, 9, R700. [CrossRef] [PubMed]

4. Truche, A.S.; Darmon, M.; Bailly, S.; Clec'h, C.; Dupuis, C.; Misset, B.; Azoulay, E.; Schwebel, C.; Bouadma, L.; Kallel, H.; et al. Continuous renal replacement therapy versus intermittent hemodialysis in intensive care patients: Impact on mortality and renal recovery. Intensiv. Care Med. 2016, 42, 1408-1417. [CrossRef] [PubMed]

5. Davenport, A.; Will, E.J.; Davidson, A.M. Improved cardiovascular stability during continuous modes of renal replacement therapy in critically ill patients with acute hepatic and renal failure. Crit. Care Med. 1993, 21, 328-338. [CrossRef] [PubMed]

6. Kruczynski, K.; Irvine-Bird, K.; Toffelmire, E.B.; Morton, A.R. A comparison of continuous arteriovenous hemofiltration and intermittent hemodialysis in acute renal failure patients in the intensive care unit. ASAIO 1993, 39, M778-M781.

7. Srisawat, N.; Lawsin, L.; Uchino, S.; Bellomo, R.; Kellum, J.A. Cost of acute renal replacement therapy in the intensive care unit: Results from The Beginning and Ending Supportive Therapy for the Kidney (BEST Kidney) study. Crit. Care 2010, 14, R46. [CrossRef] [PubMed]

8. Farese, S.; Jakob, S.M.; Kalicki, R.; Frey, F.J.; Uehlinger, D.E. Treatment of acute renal failure in the intensive care unit: Lower costs by intermittent dialysis than continuous venovenous hemodiafiltration. Artif. Organs 2009, 33, 634-640. [CrossRef] [PubMed]

9. Brivet, F.G.; Kleinknecht, D.J.; Loirat, P.; Landais, P.J. Acute renal failure in intensive care units-Causes, outcome, and prognostic factors of hospital mortality: A prospective, multicenter study. Crit. Care Med. 1996, 24, 192-198. [CrossRef] [PubMed]

10. Metnitz, P.G.; Krenn, C.G.; Steltzer, H.; Lang, T.; Ploder, J.; Lenz, K.; Le Gall, J.R.; Druml, W. Effect of acute renal failure requiring renal replacement therapy on outcome in critically ill patients. Crit. Care Med. 2002, 30, 2051-2058. [CrossRef] [PubMed] 
11. Cho, K.C.; Himmelfarb, J.; Paganini, E.; Ikizler, T.A.; Soroko, S.H.; Mehta, R.L.; Chertow, G.M. Survival by dialysis modality in critically ill patients with acute kidney injury. J. Am. Soc. Nephrol. 2006, 17, 3132-3138. [CrossRef] [PubMed]

12. Uchino, S.; Bellomo, R.; Morimatsu, H.; Morgera, S.; Schetz, M.; Tan, I.; Bouman, C.; Macedo, E.; Gibney, N.; Tolwani, A.; et al. Continuous renal replacement therapy: A worldwide practice survey. Intensiv. Care Med. 2007, 33, 1563-1570. [CrossRef] [PubMed]

13. Sasaki, S.; Gando, S.; Kobayashi, S.; Nanzaki, S.; Ushitani, T.; Morimoto, Y.; Demmotsu, O. Predictors of mortality in patients treated with continuous hemodiafiltration for acute renal failure in an intensive care setting. ASAIO 2001, 47, 86-91. [CrossRef]

14. Wald, R.; Deshpande, R.; Bell, C.M.; Bargman, J.M. Survival to discharge among patients treated with continuous renal replacement therapy. Hemod. Int. 2006, 10, 82-87. [CrossRef] [PubMed]

15. Oh, H.J.; Park, J.T.; Kim, J.K.; Yoo, D.E.; Kim, S.J.; Han, S.H.; Kang, S.W.; Choi, K.H.; Yoo, T.H. Red blood cell distribution width is an independent predictor of mortality in acute kidney injury patients treated with continuous renal replacement therapy. Nephrol. Dial. Transplant. 2011, 27, 589-594. [CrossRef] [PubMed]

16. Kellum, J.A.; Angus, D.C.; Johnson, J.P.; Leblanc, M.; Griffin, M.; Ramakrishnan, N.; Linde-Zwirble, W.T. Continuous versus intermittent renal replacement therapy: A meta-analysis. Intensiv. Care Med. 2002, 28, 29-37. [CrossRef] [PubMed]

17. Soubrier, S.; Leroy, O.; Devos, P.; Nseir, S.; Georges, H.; d'Escrivan, T.; Guery, B. Epidemiology and prognostic factors of critically ill patients treated with hemodiafiltration. J. Crit. Care 2006, 21, 66-72. [CrossRef] [PubMed]

18. Kim, E.S.; Ham, Y.R.; Jang, W.I.; Jung, J.Y.; Kwon, O.K.; Chung, S.; Choi, D.E.; Na, K.R.; Lee, K.W.; Shin, Y.T. Prognostic factors of acute renal failure patients treated with continuous renal replacement therapy. Korean J. Nephrol. 2010, 29, 54-63.

19. Gjyzaria, A.; Muzi, L.; Morabito, S. Continuous renal replacement therapy for acute renal failure in critically ill patients and early predictive factors. BANTAO 2007, 5, 58-60.

20. Lee, S.H.; Kwon, S.K.; Kim, H.Y. Outcome and prognosis in patients receiving continuous renal replacement therapy. Korean J. Nephrol. 2010, 29, 434-440.

21. Vaara, S.T.; Korhonen, A.M.; Kaukonen, K.M.; Nisula, S.; Inkinen, O.; Hoppu, S.; Laurila, J.J.; Mildh, L.; Reinikainen, M.; Lund, V.; et al. Fluid overload is associated with an increased risk for 90-day mortality in critically ill patients with renal replacement therapy: Data from the prospective FINNAKI study. Crit. Care 2012, 16, R197. [CrossRef] [PubMed]

22. Kashani, K.; Thongprayoon, C.; Cheungpasitporn, W.; Iacovella, G.M.; Akhoundi, A.; Albright, R.C. Association between mortality and replacement solution bicarbonate concentration in continuous renal replacement therapy: A propensity-matched cohort study. PLoS ONE 2017, 12, e0185064. [CrossRef] [PubMed]

23. Charlson, M.E.; Pompei, P.; Ales, K.L.; MacKenzie, C.R. A new method of classifying prognostic comorbidity in longitudinal studies: Development and validation. J. Chronic Dis. 1987, 40, 373-383. [CrossRef]

24. Levey, A.S.; Bosch, J.P.; Lewis, J.B.; Greene, T.; Rogers, N.; Roth, D. A more accurate method to estimate glomerular filtration rate from serum creatinine: A new prediction equation. Ann. Intern. Med. 1999, 130, 461-470. [CrossRef] [PubMed]

25. Bone, R.C.; Balk, R.A.; Cerra, F.B.; Dellinger, R.P.; Fein, A.M.; Knaus, W.A.; Schein, R.M.; Sibbald, W.J. Definitions for sepsis and organ failure and guidelines for the use of innovative therapies in sepsis. Chest 1992, 101, 1644-1655. [CrossRef] [PubMed]

26. Zahar, J.R.; Timsit, J.F.; Garrouste-Orgeas, M.; Français, A.; Vesin, A.; Descorps-Declere, A.; Dubois, Y.; Souweine, B.; Haouache, H.; Goldgran-Toledano, D.; et al. Outcomes in severe sepsis and patients with septic shock: Pathogen species and infection sites are not associated with mortality. Crit. Care Med. 2011, 39, 1886-1895. [CrossRef] [PubMed]

27. Prasad, B.; Urbanski, M.; Ferguson, T.W.; Karreman, E.; Tangri, N. Early mortality on continuous renal replacement therapy (CRRT): The prairie CRRT study. Can. J. Kidney Health Dis. 2016, 3, 36. [CrossRef] [PubMed]

28. Gonzalez, C.A.; Pinto, J.L.; Orozco, V.; Contreras, K.; Garcia, P.; Rodriguez, P.; Patiño, J.; Echeverri, J. Early mortality risk factors at the beginning of continuous renal replacement therapy for acute kidney injury. Cogent Med. 2018, 5, 1407485. [CrossRef]

29. Macedo, E.; Mehta, R.L. Continuous dialysis therapies: Core curriculum 2016. Am. J. Kidney Dis. 2016, 68, 645-657. [CrossRef] [PubMed] 
30. Ronco, C. Continuous renal replacement therapies for the treatment of acute renal failure in intensive care patients. Clin. Nephrol. 1993, 40, 187-198. [PubMed]

31. Da Hora Passos, R.; Ramos, J.G.; Mendonça, E.J.; Miranda, E.A.; Dutra, F.R.; Coelho, M.F.; Pedroza, A.C.; Correia, L.C.; Batista, P.B.; Macedo, E.; et al. A clinical score to predict mortality in septic acute kidney injury patients requiring continuous renal replacement therapy: The HELENICC score. BMC Anesthesiol. 2017, 17, 21. [CrossRef] [PubMed]

32. Schetz, M. Classical and alternative indications for continuous renal replacement therapy. Kidney Int. 1998, S66, S129.

33. Davenport, A. Renal Replacement Therapy for the Patient with Acute Traumatic Brain Injury and Severe Acute Kidney Injury, in Acute Kidney Injury; Karger Publishers: Basel, Switzerland, 2007; pp. 333-339.

34. Schetz, M. Non-renal indications for continuous renal replacement therapy. Kidney Int. 1999, 56, S88-S94. [CrossRef]

35. Rhodes, A.; Evans, L.E.; Alhazzani, W.; Levy, M.M.; Antonelli, M.; Ferrer, R.; Kumar, A.; Sevransky, J.E.; Sprung, C.L.; Nunnally, M.E.; et al. Surviving sepsis campaign: International guidelines for management of sepsis and septic shock: 2016. Intensiv. Care Med. 2017, 43, 304-377. [CrossRef] [PubMed]

36. Oppert, M.; Engel, C.; Brunkhorst, F.M.; Bogatsch, H.; Reinhart, K.; Frei, U.; Eckardt, K.U.; Loeffler, M.; John, S. Acute renal failure in patients with severe sepsis and septic shock-A significant independent risk factor for mortality: Results from the German Prevalence Study. Nephrol. Dial. Transplant. 2007, 23, $904-909$. [CrossRef] [PubMed]

37. Ferreira, F.L.; Bota, D.P.; Bross, A.; Mélot, C.; Vincent, J.L. Serial evaluation of the SOFA score to predict outcome in critically ill patients. JAMA 2001, 286, 1754-1758. [CrossRef] [PubMed]

38. Kawarazaki, H.; Uchino, S.; Tokuhira, N.; Ohnuma, T.; Namba, Y.; Katayama, S.; Toki, N.; Takeda, K.; Yasuda, H.; Izawa, J.; et al. Who may not benefit from continuous renal replacement therapy in acute kidney injury? Hemodial. Int. 2013, 17, 624-632. [CrossRef] [PubMed]

39. Rhee, H.; Jang, K.S.; Park, J.M.; Kang, J.S.; Hwang, N.K.; Kim, I.Y.; Song, S.H.; Seong, E.Y.; Lee, D.W.; Lee, S.B.; et al. Short-and long-term mortality rates of elderly acute kidney injury patients who underwent continuous renal replacement therapy. PLoS ONE 2016, 11, e0167067. [CrossRef] [PubMed]

40. Pistolesi, V.; Di Napoli, A.; Fiaccadori, E.; Zeppilli, L.; Polistena, F.; Sacco, M.I.; Regolisti, G.; Tritapepe, L.; Pierucci, A.; Morabito, S. Severe acute kidney injury following cardiac surgery: Short-term outcomes in patients undergoing continuous renal replacement therapy (CRRT). J. Nephrol. 2016, 29, 229-239. [CrossRef] [PubMed]

41. Soni, S.S.; Nagarik, A.P.; Adikey, G.K.; Raman, A. Using continuous renal replacement therapy to manage patients of shock and acute renal failure. J. Emerg. Trauma Shock 2009, 2, 19. [PubMed]

42. Yoon, J.; Kim, Y.; Yim, H.; Cho, Y.S.; Kym, D.; Hur, J.; Chun, W.; Yang, H.T. Analysis of prognostic factors for acute kidney injury with continuous renal replacement therapy in severely burned patients. Burns 2017, 43, 1418-1426. [CrossRef] [PubMed]

43. Bae, W.K.; Lim, D.H.; Jeong, J.M.; Jung, H.Y.; Kim, S.K.; Park, J.W.; Bae, E.H.; Ma, S.K.; Kim, S.W.; Kim, N.H.; et al. Continuous renal replacement therapy for the treatment of acute kidney injury. Korean J. Intern. Med. 2008, 23, 58. [CrossRef] [PubMed]

44. Han, S.S.; Bae, E.; Kim, D.K.; Kim, Y.S.; Han, J.S.; Joo, K.W. Dysnatremia, its correction, and mortality in patients undergoing continuous renal replacement therapy: A prospective observational study. BMC Nephrol. 2016, 17, 2. [CrossRef] [PubMed]

45. Lindner, G.; Funk, G.C.; Schwarz, C.; Kneidinger, N.; Kaider, A.; Schneeweiss, B.; Kramer, L.; Druml, W. Hypernatremia in the critically ill is an independent risk factor for mortality. Am. J. Kidney Dis. 2007, 50, 952-957. [CrossRef] [PubMed]

46. Jung, S.Y.; Kwon, J.; Park, S.; Jhee, J.H.; Yun, H.R.; Kim, H.; Kee, Y.K.; Yoon, C.Y.; Chang, T.I.; Kang, E.W.; et al. Phosphate is a potential biomarker of disease severity and predicts adverse outcomes in acute kidney injury patients undergoing continuous renal replacement therapy. PLoS ONE 2018, 13, e0191290. [CrossRef] [PubMed]

47. Kraft, M.D.; Btaiche, I.F.; Sacks, G.S.; Kudsk, K.A. Treatment of electrolyte disorders in adult patients in the intensive care unit. Am. J. Health-Syst. Pharm. 2005, 62, 1663-1682. [CrossRef] [PubMed]

(C) 2018 by the authors. Licensee MDPI, Basel, Switzerland. This article is an open access article distributed under the terms and conditions of the Creative Commons Attribution (CC BY) license (http:/ / creativecommons.org/licenses/by/4.0/). 